\title{
USING REFLECTIVE PRACTICES TO EXPLORE POSTGRADUATE STUDENTS SELF-DIRECTED LEARNING READINESS IN MOBILE LEARNING PLATFORM AND TASK-CENTERED ACTIVITY
}

\author{
Malini THIAGRAJ \\ ORCID: 0000-0002-9521-1665 \\ School of Education \\ Universiti Utara Malaysia \\ Sintok, Kedah, MALAYSIA \\ Dr. Abdul Malek ABDUL KARIM \\ ORCID: 0000-0002-4268-4338 \\ School of Education \\ Universiti Utara Malaysia \\ Sintok, Kedah, MALAYSIA \\ Dr. Arsaythamby VELOO \\ ORCID: 0000-0002-6827-082X \\ School of Education \\ Universiti Utara Malaysia \\ Sintok, Kedah, MALAYSIA
}

Received: 27/07/2020 Accepted: 12/08/2020

\begin{abstract}
The purpose of this study is to explore postgraduate students' self-directed learning (SDL) readiness using Mobile learning (M-learning) in Massive Open Online Courses (MOOCs) as a platform and task-centred activity. Reflective practice is used to measure students SDL readiness. This study is qualitative in nature. The research employed thematic analysis method, which involved systematic coding processes, entailing coding, finding categories and themes. Hence, 34 postgraduate students from a public university were selected via a purposive sampling method. They were initially introduced to M-learning course content in FutureLearn (MOOCs) platform, followed by reflective practices. Pre-reflective practices happened before students were enlisted into the M-learning process, During-reflective process in FutureLearn platform and Post-reflective upon completion of the task-centered activity. The findings revealed that most of these students were not sure of their own readiness to take on SDL in the M-learning platform during the pre-reflective stage. However, most of them were able to monitor their own readiness at the During-reflective process. Subsequently, they made progress in adopting and self-evaluating their own performance by completing the task-centered activity successfully. Therefore, the contribution of this study is on constructing reflective practices based on three different stages. Hence, the reflective approach practice has given students insight on their own learning capabilities and readiness for SDL in the mobile platform.
\end{abstract}

Keywords: Self-directed Learning (SDL), readiness, FutureLearn (MOOCs) platform, Reflective practice, Task centered activity.

\section{INTRODUCTION}

"We can only have citizens who can live constructively in this kaleidoscopically changing world if we are willing to become self-starting and self-initiating learners", said Carl Rogers' in 1968. In alignment with Rogers' statement, to be effective in the 21 st century, learners are required to be self-initiative in creating, evaluating and effectively utilizing easily accessible information. Thus, the 21 st-century learners or digital learners are expected to be connected, self-directed, mobile (Tulagan, 2013; Rashid \& Asghar, 2016; Jaleel \& Anuroofa, 2017) and able to access more information than the previous generation (Fahnoe \& Mishra, 2013). 
Self-directed learning (SDL) readiness provides a more direct route into understanding the actual dynamics of mobile learning (M-learning) by examining the degree at which the self-directed learner takes personal control and acknowledges freedom (Fisher, King, \& Tague, 2001). The author also added that freedom is closely associated with learning what the students' consider as important. Self-directed learners can be likened to active learners as they are able to establish their own knowledge by planning, monitoring, managing the learning materials as well as the learning process, reflect on their learning and evaluate it individually (McLoughlin \& Lee, 2010; Lee, Tsai, Chai \& Koh, 2014). The immediate access to modern educational technologies and M-learning resources strengthened and broadened the capacity for self-directed learners to enhance their own knowledge autonomously by taking control over the learning process.

Self-directed learning empowers students' to take control over their own learning by accepting the freedom to learn what they consider important for themselves. Yet, SDL is changing the way students think about work. The M-learning platform for SDL learners has its' pros and cons. Therefore, students should have the cognitive ability to diagnose and analyse the pros and cons of mobile devices for learning rather than not falling aside due to mobile distraction. Therefore, reflection is an essential practice for students to encourage thinking about one's own learning. In addition, Diaz (2015) investigates the effects of reflection to help beginning young learners in the learning process.

However, there has been little discussion on postgraduate students reflective practices as regarding the use of SDL readiness (Toh \& Kirschner, 2020; Camargo, Bary, Boly, Rees, \& Smith, 2011; Kek, \& Huijser, 2011) in the M-learning platform. Therefore, the research question of this study is to explore the postgraduate students SDL readiness using reflective practices on task-centred activities based on the FutureLearn (MOOCs) platform. Thus, reflective practices (pre-, during-, and post-reflective) has been employed to explore the postgraduate students readiness towards SDL in the M-learning platform. The rationale behind employing these reflective practices is based on Schon's (1983) ideas in his writing "The reflective practitioner". Schon identified these reflective practices as a vital element which enables students to be aware of ones' implicit knowledge and comprehend the experience of learning.

\section{LITERATURE REVIEW}

\section{Self-directed Learning Readiness in Mobile Learning Platform}

In this digital age, the learner needs to be more alert and aware of receiving any kind of information which is easily available in the online learning platform. This is because the learner has control over their own learning and they also have immediate and quick access to all kinds of information without any filtration. Zimmerman (2008) argued that online learning platform has the potential to improve the learning process, and at the same time require skills like goal setting, monitoring, controlling cognition and motivation. Moreover, he argued that the improvement of the M-learning environment can assist the students in using a self-regulated learning model as guidance (Zimmerman, 2008).

García Botero, Questier, and Zhu (2019) examined on the mobile assisted language learning foster selfdirected learning outside the classroom among 118 postgraduate students. The findings reveal a lack of sustained motivation, self-monitoring and self-management reflected in the low usage of the mobile application.

Song, Bonk, and Whiting (2012) stressed that a huge number of learners prefer to use open and free online learning resources during personal learning experiences like MOOCs. Learners have the freedom to learn at their own pace from these online learning resources as this gives a crucial impact on the learners attitudes and beliefs regarding learning. Besides that, Sridharan, Deng, Kirk, and Corbitt (2010) mentioned that technological facets, management of the technology, and learning resources as well as material organizations are the main factors which influence the effectiveness of learning through online resources.

McLoughlin and Lee (2010) stated that self-directed learners establish their own knowledge by examining, managing, reflecting and evaluating their learning materials as well as the learning process. The easy access to modern educational technologies and M-learning strengthened and broadened the capacity for self-directed learners. Dunlap and Lowenthal (2011) supported by adding that recent technologies can help students to enhance their problem-solving skills and reflective practices. 
Lai, Li, and Wang's (2017) conducted a research on pre and post survey analyses focused on language learners' self-direction and technology use. The finding proved the importance of learners' positivism on technology and developed beliefs on technology use. Another study was conducted by Sirakaya, Ozdemir and Selcuk (2018) on the effect of flipped classroom and self-directed learning readiness by comparing with blended learning method. The findings of this study shows significant difference between both groups.

García Botero et al. (2019) investigated factors influencing students' self-directed learning with technology. A questionnaire was employed to obtain data from 153 students on their self-directed learning readiness with the use of Web 2.0 tools for learning. The findings revealed that the students' self-directed learning readiness and the Web 2.0 tools for learning, had a statistically significant direct contribution to SDL with technology.

Lee, Yeung, and Ip (2017) investigated university students in Hong Kong and found a positive correlation between self-directed learning construct and technology. The constructs include learning desire, learning management, and learning control. Among this construct, the learning desire was strongly influenced by technology usage. In another study, Hsu (2017) developed and compared self-directed learning and taskcentered learning. The author revealed that the potential of self-directed learning and task-centered learning aid in developing effective learning.

\section{Reflective Practices}

John Dewey (1933) introduced about the concept of "reflective thinking" in his book "How We Think" to represent "active, persistent, and careful consideration of any belief or supposed form of knowledge in the light of the grounds that support it and the further conclusion to which it tends" (Dewey, 1933, p.9). In his book, reflection involves the learner as the object of reflection.

In 1987, Donald Schon in his book of "The Reflective Practitioner: how professionals think in action" stated that a learner who practices reflective thinking is aware of own cognition and the constant cognition enabled the learner to have a solution which is out of the box thinking. Meaning, the learner recognizes that every given problem or interpretation of a circumstance may have more than one solution if the learner practices and continues thinking. Schon (1987) created the first term of "reflection-in-action as a thought that a learner takes while involved in a circumstance, during which the learner become aware of what one is thinking, feeling and doing and the second term of reflection-on-action takes place sometime later, when the learners consider the events that took place, and recall what the learners were thinking, feeling and doing" (Hickson, 2011, p.831). Later, Thompson (2008) added another dimension to this practice called reflection-for-action, which is planning ahead and reflecting on what may happen, allowing for preparation and anticipation of a situation. Therefore, this study has employed the same process of the three phases (pre, during and postreflective) as what Schon (1987) and Thompson, (2008) mentioned in their studies. Substantively, this study used Gibbs' reflective cycle as a guide in designing the three reflective questions.

There are several reflections models in the literature (Gibb's reflective cycle, Atkins \& Murphy, 1994; Bass, Fenwick, \& Sidebotham, 2017), hence this study chose Gibbs' reflective cycle as it helps the postgraduate students to think systematically about the different stages of their learning experience (Helyer, 2015). A study conducted by Ahmed (2019) employed Gibbs' reflective cycle to develop a reflective journal to help students at Qatar University to reflect on the instructional practices. Thus, this study is used a case study methodology and the data analysed using content analysis. The findings of the study revealed that students preferred teaching strategies such as gradual teaching, exemplification, discussion, comprehension checking, cooperative learning, and graphic organizers. In another study conducted by Mohamed Abdullah Turky (2016) aimed to investigate web 2.0 application usages in promoting reflective thinking skills for higher education students in the faculty of education. Thus, this study is used Gibbs' reflective cycle to foster reflective thinking skills. The findings of this study provided the students skills throughout the learning process. Another findings is a professionally reputable and methodologically rigorous evidence base for learning and teaching innovation.

The researcher explored the use of reflective practices in identifying postgraduate students SDL readiness in M-learning platform. Substantially, these students have been evaluated used task-centered activity to 
determine their readiness level in SDL. These students were introduced to FutureLearn (MOOCs) platform which is one of the M-learning platforms and the reflective practices (pre-, during-, and post-reflective) take place throughout the M-learning process. To strengthen this study, the researcher used a self-regulatory learning model (Zimmerman, 2002) as a theoretical framework. Using these three reflective practices, this study explores the students SDL readiness in M-learning.

\section{Self-regulated Learning Model}

The self-regulated learning (SRL) model and cycle incorporated certain cognitive strategies like planning, monitoring and evaluating (Zepeda, Richey, Ronevich, \& Nokes-Malach, 2015). This model categorizes the three phases as forethought, performance, and self-reflection (Zimmerman, 2002; Zimmerman \& Schunk, 2011). Each phase includes several important sub-processes (Zimmerman, 2002). To strengthen this study, the researcher has used the self-regulated learning model where the pre-reflective stage is used as a forethought phase, during the reflective stage, it is regarded as performance phase and the post-reflective stage as a selfreflective phase which incorporates with cognitive strategies like planning, monitoring and evaluating. The reason for employing this model is to understand the students readiness towards SDL at every stages (Pre-, During- and Post-reflective) during the online learning process (Figure 1).

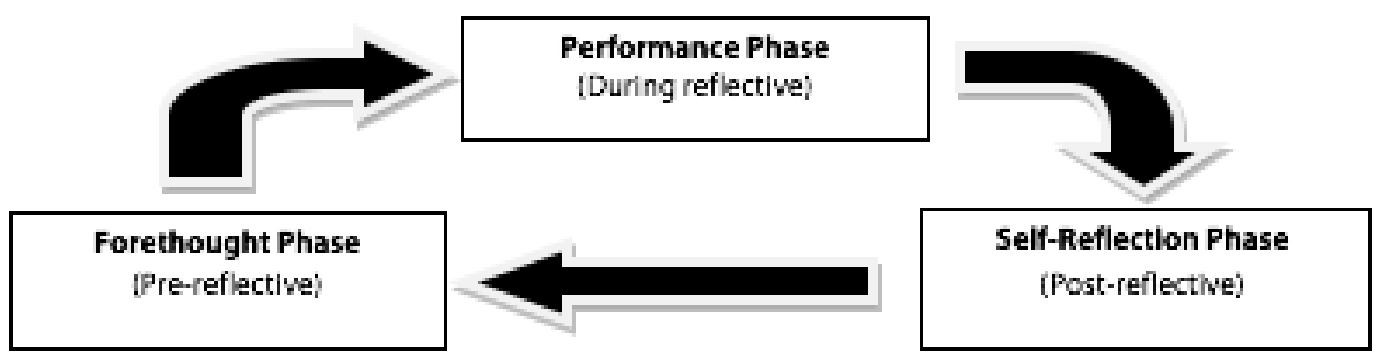

Figure 1. Phases and sub-processes of self-regulated learning (SRL), adapted by Zepeda, Richey, Ronevich, \& Nokes-Malach, (2015).

\section{The Role of Instructor as Facilitator}

The role of the instructor has transformed from being 'the source of knowledge' to a facilitator and role model in the process of acquiring knowledge and skills (Moodleroom, 2012). Therefore, "instructors need to provide learners with learning experiences that foster self-directed learning, get learners actively involved in one's own learning process, and explicitly teach learners how to learn while guiding the learning process" (Francom, 2010, p.29). In addition, Rico and Ertmer (2015) examined the role of the instructor employing student-centered approaches, specifically those that are problem-centered, result in outlining effective strategies that are valuable for facilitating discussions. Therefore, the instructor role in this study would facilitate regulations of cognitions in an interaction between the content (The FutureLearn course design) and the learner as a teaching presence. The interaction between instructor and learner are assumed to foster readiness towards self-directed learning in the M-learning (Garrison, 2015).

\section{METHODOLOGY}

This study is qualitative in nature and employed thematic analysis to identify the postgraduate students SDL readiness using reflective practices. This study used purposive sampling in choosing the 34 postgraduate students from Instructional Technology (IT) course in one of the public universities in Malaysia. Furthermore, a self-regulated learning model was used as a theoretical framework, while Gibbs' reflective cycle (1988) was employed to design reflective questions with some guiding questions to probe postgraduate students' reflections at three different stages in the M-learning process. FutureLearn was also employed in the study, as it is one of the M-learning platforms. An online course which is Blended Learning: Getting 
Started' from FutureLearn platform was used as well. The whole M-learning process lasted up to 8 weeks and the reflective practices took place before the students enrolled in the M-learning process (pre-reflective), during the FutureLearn platform courses learning (during-reflective) and after completing the task-centered activities (post-reflective).

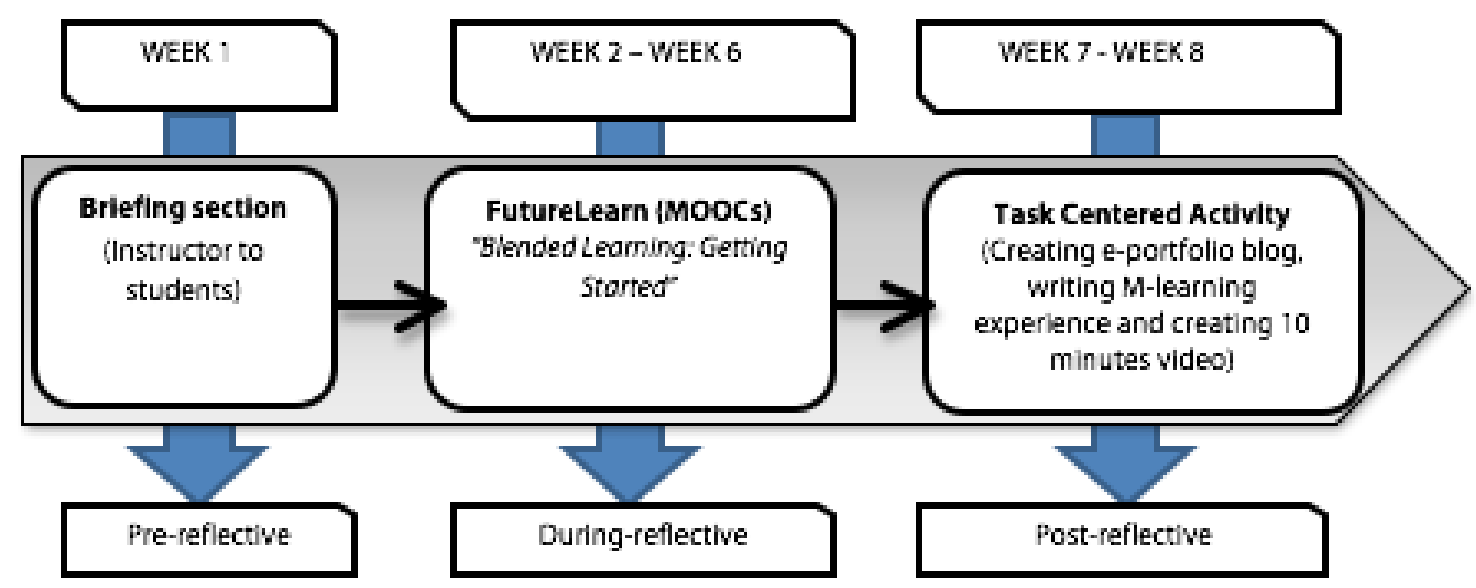

Figure 2. The Reflection Learning Process

\section{Postgraduate Students Background}

The total number of Postgraduate students from Instructional Technology (IT) course is 34 individual which comprise of $7(20.5 \%)$ male and $27(79.5 \%)$ female. This study showed that the frequency of the students year of studies enrolled into IT course is from the first year with $26(76.6 \%)$ students and followed by a second and third year with $4(11.7 \%)$ students. The postgraduate students who enrolled in IT course with different program of studies which is Instructional Technology and Educational Psychology of 9 (26.5\%) students, English Language Teaching with 7 (20.6\%) students, Curriculum \& Instruction with 6 (17.6\%) students and Islamic Education with 3 (8.8\%) students.

\section{Reflective Questions}

This study chose Gibbs' reflective cycle as it helps the postgraduate students to think systematically about the different stages of their learning experience (Helyer, 2015). The Gibbs' model provided a guiding structure and some cue questions to answer which aids the students reflection on the SDL readiness in the M-learning environment. Therefore, this study adapted Gibb's Reflective Cycle (1988) model to construct items for reflective practices. There are six sections in this model and the first two sections (description and feelings) measures pre-reflective with 5 questions. The next two sections (evaluation and analysis) measured during reflective consists of 12 questions. The last two sections (conclusion and action plan) measured the postreflective phase and consist of 15 questions. Two experts from a public university in IT in the education field reviewed and validated these reflective questions. Besides that, member checking was carried out by permitting the postgraduate students to review the reflective questions for validation purposes. The data from the reflective questions were analysed using the thematic analysis method which involved a systematic coding process which entails coding, finding categories and themes.

\section{Data Collection}

The data were collected at three different stages. 


\section{Before the M-learning Process (1 ${ }^{\text {st }}$ Briefing section on Week 1).}

In the briefing section which takes part before the postgraduate students enrolled in the M-learning process, the researcher of this study introduced herself and explained the intention and purpose to conduct this study to all the 34 postgraduate students enrolled in the Instructional Technology (IT) course. After the small introduction, the researcher provided the URL of the Google form where the pre-reflective questions were uploaded online and requested the postgraduate students to access the URL using their mobile devices. The rationale behind uploading the reflective questions online is to ease the students learning process as well as to foster online self-report learning experience. Later, the researcher explained the pre-reflective questions precisely and ensured that the postgraduate students understood them. After the brief explanation, the researcher allowed the postgraduate students to answer the pre-reflective questions and 15 minutes time duration was given in order to complete them. After the briefing section, the researcher of this study explained and demonstrated the features and course content on the FutureLearn (MOOCs) platform. The course that the postgraduate students needed to attend is stated thus "Blended learning: Getting started", which runs for five weeks. After the brief explanation, the postgraduate students were allowed to register and enrolled in the FutureLearn (MOOCs) platform at their own pace.

\section{During the M-Learning Process (Week 2 - Week 6).}

The postgraduate students started enrolling into the M-learning platform and while engaging, the researcher of this study uploaded the second reflective questions (during-reflective) in the Google form. The researcher personally emailed all the postgraduate students with the second reflective questions. Three weeks duration was given to the postgraduate students to answer the during-reflective questions and the questions were submitted online back to the researcher. The researcher tracked and recorded all the postgraduate students' responses to the reflective questions. A friendly reminder email was sent to those who had not yet responded.

\section{Second Briefing Sections on Week 7.}

During the second briefing, the researcher distributed the task-centered activity questions to the postgraduate students. The researcher informed that the postgraduate students had two weeks to complete the activities in the task-centered activity. The task-centered activity consisted of three activities of which the postgraduate students' needed to create an e-portfolio blog, write reflections on M-learning experience and create a 10 minutes video presentation based on M-learning experiences.

\section{During the Task-centered Activity (Week 7 - Week 8).}

The postgraduate students started doing the task-centered activity. Two weeks duration was given to do the task-centered activity based on their M-learning experiences. The role of the researcher in this study was to facilitate and provide timely support and guidance to the struggled novice students.

\section{End of the Task-centered Activity (Week 8).}

In week eight, the postgraduate students were required to email their blog URLs to the researcher. Every student had their own individual blog URL to exhibit their work. The researcher recorded all the 34 postgraduate students' blog URLs. The postgraduate students' task-centered activity were evaluated based on the rubric. After gathering all these 34 postgraduate students blog URLs, the researcher requested the students to access the online post-reflective questions in Google form. The researcher allocated the students' 15 minutes to answer the post-reflective questions and had them submitted back to the Google form. Upon completion, all the students were dismissed. 


\section{Data Analysis}

Guided by the research question and Gibbs' reflective cycle, postgraduate students reflective practices were analysed using thematic analysis (Radnor, 2001) which come up with three themes. However, to distinguish the level of SDL readiness, postgraduate students were assessed based on their competency in performing the task-centered activity. The task-centered activity was evaluated based on $100 \%$ marks, but this score (100\%) is measured using rubric adapted from Harry Walker, Johns Hopkins University (2010). This rubric is based on four levels which are a novice (0-25\%), basic (25-50\%), proficient (50-75\%) and advanced (75-100\%).

\section{FINDINGS}

From the analysis of the data, three distinct themes were identified. Aligning with a Self-Regulated Learning theory framework (Boekaerts, 1999) each identified theme is discussed thoroughly supported with the related literature.

\section{Pre-reflective Activity on Students SDL Readiness}

At the beginning stage, most of the postgraduate students mentioned that they were "unsure of SDL readiness in M-learning". This showed that the students were not sure of their readiness on SDL in the FutureLearn platform and unable to plan any strategy as they lacked prior knowledge. These students were affirming that they do not have prior knowledge or experience of doing tasks independently or with less supervision in the online learning platform. Thus, these students were not ready to do the activity or task without the instructor's supervision. Besides that, several students who are aware of SDL mentioned that it is a process in which an individual takes the initiative in diagnosing the learning needs with or without the help of others on a daily life basis. Other than that, the students also agreed that M-learning increased readiness towards SDL as technology makes their life easier and increased the interest to learn more. Therefore, these students mentioned that they are ready to embrace the online learning platform as they can perform the task and direct their learning with the fast-evolvement of M-learning. The pre-reflective practice permitted the students to brainstorm on this new learning endeavor and prepared them to get familiarized with the FutureLearn platform employing mobile devices. However, few students claimed that they will be able to direct their learning if the activities or task instructions are clear and easy to understand. They also highlighted their willingness to do the task if proper guidance from the instructors were provided. The guidance from an instructor is important when the students are faced with difficult activities or tasks.

"No as I have no experience in doing task assigned independently" (S3).

"Individuals take the responsibility to learn on their own" (S2).

"Yes, because everything is easy at the current situation as we get more guidance with the technology" (S18).

"Yes, anything is possible with the Internet and YouTube which helps in self-learning which help me to build better understanding of what we are learning" (S22).

"I am not familiar doing online learning platform before without instructor guidance" (S25).

"Yes, but anyhow guidance needed for complicated questions or tasks" (S1).

\section{During-reflective Activity on SDL Readiness}

At this stage, the students started to monitor their own readiness as a self-directed learner in the FutureLearn platform, employing their own mobile devices. The students reported that they are able to monitor themselves to be more independent, self-confident and self-disciplined while developing love towards learning and the ability of time management and self-management. Proficient students conceded that they are punctual, self-motivated, well-organized, self-learning future-oriented, and creative. There were some students who mentioned that they learned to find solution for the obstacles faced during this M-learning process. Hence, these students described that they were able to monitor their learning progress and adapt their search strategies during this M-learning process. Through monitoring, students can control and direct 
their learning and ensure if a selective strategy is working or not or is needed to make adjustment. This stage reflected on the students' self-awareness of their learning and this can improve their understanding of content concept and problem-solving skills.

"I learned to motivate myself and gained more self-confident and self-discipline"(S5).

"I am well disciplined and was able to progress with blended learning"(S22).

"Sometimes i can manage to complete a task that i couldn't believe i can do it"(S35).

"Need to be more focused and able managed time" (S13).

"I was to be punctual and well organized". (S18)

"Time management and self-management are very important for a part-time learner"(S11).

"There are many more creative and innovative ways in delivering an effective class"(S8).

"I learned to manage myself to find solution when faced any obstacles in order to complete the task" (S19).

However, there are few students who reported that they are less likely to be self-directed learners in the M-learning platform. These students reported that they have less confidence when engaging in the M-learning platform. Lack of confidence demotivated the students to engage more in M-learning and condensed their interest to explore more in this FutureLearn platform. Few students admitted themselves as slow learners and technologically not fit to engage in the FutureLearn platform. Therefore, these students felt that the FutureLearn platform sounds very challenging and needed constant instructor guidance throughout the M-learning process.

"I am feeling less self-confident and not independent"(S33).

"Need more hardworking and I often give up"(S15).

"It very difficult and challenging but i needs more guidance"(S9).

"I am a slow learner actually and need more guidance" (S19).

\section{Post-reflective Activity on SDL Readiness}

At this final stage, the students' ability to evaluate their effort and strategies in completing this FutureLearn platform and task-centered activity successfully was examined. Thus, most of the students reported that they have more confidence in a positive outcome resulting from independent learning in the FutureLearn platform and task-centered activity. These activities permitted the students to face challenges, especially when they have to accomplish the lesson on a given timeframe and task with less supervision from their instructors and away from the classroom boundaries. Some students responded that they develop more love for challenges and enhance self-discipline. Several students expressed that this FutureLearn platform and task-centered activity enabled them to learn new knowledge as well as increased creativity, ability to use problem-solving skill and self-assessment. Hence, at this stage, these students managed to complete the task-centered activity based on their autonomous learning in the FutureLearn platform. These students felt overwhelmed with the effort invested in the M-learning as they felt appreciative on gaining new knowledge and exposure.

"I will make sure I put a full effort to complete it as I did for before"(S19).

"I am feeling enjoyed and $i$ also complete the FutureLearn and Activities"(S25).

"This platform increases my self-confident and love challenging"(S13).

Nevertheless, some students reported that they felt insecure when required to do the task without their instructor's physical supervision. Thus, the student felt that they lack self-confidence and self-discipline. Few students mentioned that they felt lost during learning when there is a lack of proper guidance or prior knowledge. Therefore, these students mentioned that they need the guidance of an instructor. However, meaningful learning experience has shifted the students to be proficient in mobile technology. Despite, the 
lack of confidence and feeling of insecurity without instructor supports, the students managed to complete the task-centered activity.

"I felt insecure as I am not good in technology and without instructor physically make me feel inconvenient to learn more" (S25).

"I felt lack of self-confident as I am not good in technology"(S13).

"I am not good in this FutureLearn and I can't discipline myself well"(S16).

"I need guidance from instructors as I am not confident to do alone"(S26).

"I able to complete the task even without the instructor support"(S15).

\section{Assessment on Task-centered Activity}

Students' task-centered activity performance has been assessed using rubric which measured by four levels such as novice, basic, proficient and advanced. Therefore, no novice level students have been recorded meanwhile six students have obtained a score between 25 to $50 \%$ which belongs to a basic level. Continuing in the same vein, 18 students have obtained a score of about 50 to $75 \%$ which is proficient level followed by 10 students have obtained score about 75 to $100 \%$ which is an advanced level. Therefore, most of the students entailed into proficient and advance level while six students entailed into basic level (Table 1).

Table 1. Students Score in Task-centered Activity

\begin{tabular}{ccc}
\hline Score & Performance Indicator & Student achieved \\
\hline $0-25$ & Novice (1) & 0 \\
$25-50$ & Basic (2) & 6 \\
$50-75$ & Proficient (3) & 18 \\
$75-100$ & Advanced (4) & 10 \\
\hline & & 34 \\
\hline
\end{tabular}

\section{DISCUSSION}

The first main finding of the pre-reflective stage is that, majority of the students were unsure of their SDL readiness in the M-learning platform. These students reported that the lack of exposure in the FutureLearn platform to work autonomously is indeed challenging when it comes to real-time experience. These students came clueless in handling the FutureLearn platform as they had no idea of what to do at this initial phase. They also were unaware of developing any strategy or transferring the prior knowledge. Although students were unsure of transferring prior knowledge, they were able to regulate their cognition on preparing themselves to direct the learning. Therefore, students slowly self-orientated and got themselves familiarized with this M-learning platform. Despite that, some students mentioned that lack of readiness towards SDL does not stop them from embracing the M-learning independently if the activity or task is easy to understand. Thus, the finding is consistent with findings from Zimmerman (2008), who mentioned that online learning platform has the potential to improve the learning process and require skills like goal setting, planning, controlling cognition and motivation. He argued that the improvement of a high-tech learning environment can assist the students' in using self-regulated learning strategies.

The second main finding during the reflective stage was that, the students adopted the M-learning and gradually got used to the FutureLearn platform, as they developed their own strategy based on their learning experiences. The students did not only monitor the action but also kept track of the progress towards their goal settings. The students reflective practices empowered them to self-instruct, self-monitor and make decision on their learning. Moreover, most of the students became more independent, self-confident and self-disciplined while developing love towards new learning experiences as they started to enjoy this M-learning platform. Additionally, the students developed the ability of time management and self-management despite their hectic schedule and 
family commitment. Therefore, these findings are in line with García Botero et al. (2019). The students' selfdirected learning with Web 2.0 tools had a statistical significance direct contribution to SDL with technology. The learners' attitude, abilities, and personality traits which is needed for SDL is more likely to influence the use of technology as they get benefit for it. However, there are several students who encountered difficulties to monitor their own cognition, as they were not ready to be self-directed and were technological illiterates in M-learning. Quite common, less self-confidence and feeling of fear demotivates and lower the interest of the students to get engaged in the M-learning platform. Due to a lack of self-confidence, some of the students claimed themselves as slow learners and found M-learning to be difficult and challenging. These students also mentioned that they need constant instructor guidance throughout the M-learning process. Therefore, these findings are consistent with findings from Fournier, Kop, and Durand (2014), who stated that students with a lack of personal attributes will reflect on low self-direction and self-interest in one's learning and not all students have the ability to regulate cognition skills. Also, Azevedo and Cromley (2004) stated that the students reported with only basic technology knowledge are inadequate to do the online courses.

The third main finding of the post-reflective stage is the students' ability to adopt and evaluate their effort and strategies in completing the FutureLearn platform and task-centered activity successfully. Thus, these students developed more self-confidence in working independently to gain meaningful learning experiences. These activities permitted the students to face challenges, especially when they have to accomplish lessons and task with less supervision from their instructors and away from the classroom boundaries. Apparently, students were provoke to be self-directed learners as they set in positions to figure out solutions for the obstacles faced during learning in the M-learning platform and task-centered activity. Students evaluated that the M-learning empowered them to be self-directed learners as they gained more confidence out of this learning experience. At the end of this learning process, students developed self-confidence, self-discipline, love challenges, freedom for making their own decision, increased creativity and ability to use basic skills and problem-solving skills. These findings complement Rivenburg (2015) findings, which stated that learners' learning strategies in setting and attaining goal are essential in self-regulation of learning. When the learner become familiar with their own learning strategies, then they are more likely to apply the favored skills and strategies to the learning process. Also according to Rashid and Asghar (2016), the use of technology has a direct positive relationship with students' engagement and self-directed learning. Nevertheless, some students reported that they felt insecure and less confident when required to do the task without their instructor's physical supervision. Therefore, these students found that the role of the instructor as a facilitator smoothens the learning process, which is in line with what Rico and Ertmer (2015) mentioned about the role of the instructor as a facilitator in the M-learning platform. Hence, these reflective practices have pushed the students to think and comprehend the benefit of M-learning as well as increased SDL readiness. Despite, the lack of confidence and feeling of insecurity without instructor's support, the students managed to complete the task-centered activity successfully. This finding is consistent with Hsu (2017) on revealing the potential for self-directed learning and task-centered learning in developing effective learning. Besides that, this study corroborated with Ahmed (2019) study by employing Gibbs' reflective cycle to develop a reflective journal to help students reflect on the instructional practices. The findings of the study revealed that students preferred teaching strategies such as gradual teaching, exemplification, discussion, comprehension checking, cooperative learning, and graphic organization.

\section{LIMITATION AND FUTURE STUDY}

The present reflective practice has many limitations. It is also important to note that about half of the samples of this study were from a particular Higher Educational Institution (HIE). This results may not be generalizable to students at other HEIs or other contexts of learning. Regardless, one outcome that can be generalized is the fact that the students who participated in this study were adult learners. Furthermore, SDL readiness and Gibbs' reflective cycle were self-reported reflective practice writing, which may vary based on subjective bias. However, this study recommend determining the teaching needs and readiness among IT postgraduate students towards SDL in the M-learning environment. Further, since student's M-learning platform is a construct that can be improved, it is suggested that instructors should take into consideration other sources of M-learning and thus try to implement among students in real-time experiences. Moreover, the outcome from this study may help instructors focus on interventions that can foster the development of the cognitive skills of students which accommodate students' strengths and ability level. 


\section{CONCLUSION}

The reflective practice at three different stages has given students' the insight to think about one's learning capabilities, thus gradually improving the SDL readiness in the M-learning platform. This study has found that reflective practice has a significant impact on increasing the postgraduate students' SDL readiness in M-learning platform and subsequently to perform any task-centered activity. Thus, it is an essential practice which allows the students to think about their own cognitive load. Hence, there are strong arguments for paying more attention to the adoption of SDL in higher education institutions to encourage lifelong learning. The SDL empowers the students to develop an ability to apply and acquire knowledge, recognize the problem and develop an appropriate solution using mobile tools for effective M-learning.

\section{BIODATA and CONTACT ADDRESSES of AUTHORS}

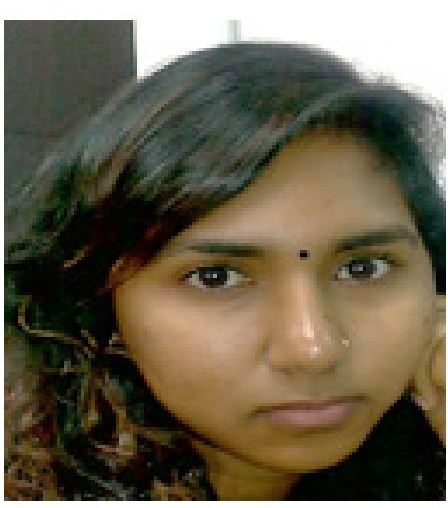

Malini THIAGRAJ is a Ph.D. candidate of Instructional Technology at the School of Education, Universiti Utara Malaysia. She obtained her Bachelor's degree from the AIMST University and Master's degree from the Universiti Utara Malaysia, Malaysia. For the last five years, she has been researching on educational technology and mobile technology integration in education. She also worked as International School Teacher in the field of Information Technology. She has 4 journal articles published in national and international indexes. Her interest areas are M-learning, E-learning, Mobile technology, mobile-based assessment and Self-directed learning.

Malini THIAGRAJ

College of Arts and Science, School of Education,

Universiti Utara Malaysia

Sintok, Kedah, Malaysia

Phone: +60149468603

E-mail: malini85t@gmail.com

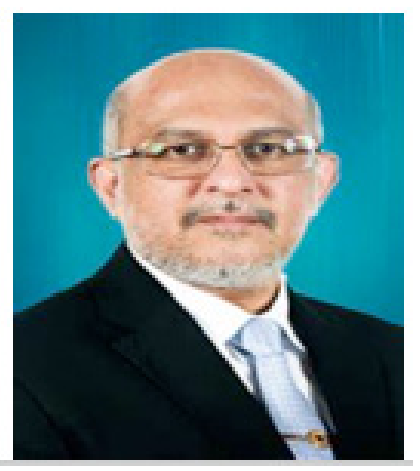

Prof.Dr. Abdul Malek ABDUL KARIM is a Professor of Instructional Technology at the School of Education, Universiti Utara Malaysia. He is currently the Director of UUM Information Technology. He obtained his Bachelor's degree from the Victoria University of Wellington, New Zealand, Master's degree from the University of Edinburgh, United Kingdom and a Doctor of Education from the University of Virginia, United States of America. His current research interests include the use of interactive technologies for remote learning, the ethical issues in online education and students ability to adapt from face to face instructor to computer-based training in a virtual classroom environment.

Abdul Malek ABDUL KARIM

UUM Information Technology

School of Education, Universiti Utara Malaysia Sintok, Kedah, MALAYSIA

Phone: +60 (04) 9282250

E-mail:malek@uum.edu.my 


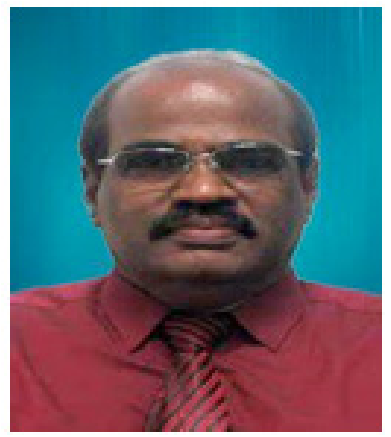

Prof.Dr. Arsaythamby VELOO is a Professor of School of Education at Universiti Utara Malaysia (UUM). He gained his Ph.D. in Psychometric and Educational Testing at 2006. His academic interest areas are Psychometrics, Measurement, Testing and Evaluation, Educational Psychology, Statistics in Education, Educational Mathematics, Research Methodology and Management. He has many journal articles, book chapters and papers published to international meetings. He supervised $\mathrm{PhD}$ and master theses.

Arsaythamby VELOO

School of Education, Universiti Utara Malaysia Sintok, Kedah, MALAYSIA

Phone: +60194774997

E-mail: arsay@uum.edu.my

\section{REFERENCES}

Ahmed, A. M. (2019). Students' reflective journaling: an impactful strategy that informs instructional practices in an EFL writing university context in Qatar. Reflective Practice, 20(4), 483-500. https:// doi.org/10.1080/14623943.2019.1638246

Atkins, S., \& Murphy, K. (1994). Reflective practice. Nursing Standard, 8(39), 49-56.

Azevedo, R., \& Cromley, J. G. (2004). Does Training on Self-regulated Learning Facilitate Students' Learning with Hypermedia? Journal of Educational Psychology, 96(3), 523-535.

Bass, J., Fenwick, J., \& Sidebotham, M. (2017). Development of a Model of Holistic Reflection to Facilitate Transformative Learning in Student Midwives. Women and Birth, 30(3), 227-235.

Boud, D., Keogh, R. \& Walker, D. (1985) Promoting Reflection in Learning: a Model. New York.

Boekaerts, M. (1999). Self-regulated Learning: Where We Are Today. International Journal of Educational Research, 31(4), 445-457. doi: 10.1016/S0883-0355(99)00014-2.

Bower, P. (2003). Efficacy in Evidence-based Practice. Journal of Clinical Psychology and Psychotherapy, 10(6), 328-336.

Cho, M., \& Heron, M. (2015). Self-regulated Learning: the Role of Motivation, Emotion, and Use of Learning Strategies in Students' Learning Experiences in a Self-paced Online Mathematics Course. Distance Education, 36(1), 80-99.

Dunlap, J. C., \& Lowenthal, P. R. (2011). Learning, Unlearning, and Relearning: Using Web 2.0 Technologies to Support the Development of Lifelong Learning Skills. In G. D. Magoulas (Ed.), E-infrastructures and technologies for lifelong learning: Next generation environments (pp. 4652). Hershey, PA: IGI Global.

Dewey, J. (1933). How we think: A Restatement of the Relation of Reflective Thinking to the Educative Process. Chicago IL: Henry Regnery Co.

Diaz, I. (2015). Training in Metacognitive Strategies for Students' Vocabulary Improvement by Using Learning Journals. PROFILE Issues in Teachers' Professional Development, 17(1), 15-23.

Fahnoe, C., \& Mishra, P. (2013). Do 21st century Learning Environments Support Self-directed Learning? Middle School Students' Response to an Intentionally Designed Learning Environment. In R. McBride \& M. Searson (Eds.), Proceedings of Society for Information Technology \& Teacher Education International Conference 2013 (pp. 3131-3139). Chesapeake, VA: AACE.

Fisher, M., King, J., \& Tague, G. (2001). Development of a Self-directed Learning Readiness Scale for Nursing Education. Nurse Education Today, 21(7), 516-525. 
Fournier, H., Kop, R., \& Durand, G. (2014). Challenges to Research in MOOCs. MERLOT Journal of Online Learning and Teaching, 10(1), 1-15.

Francom, G. M. (2010). Teach me how to learn: Principles for Fostering Students' Self-Directed Learning Skills. International Journal of Self-Directed Learning, 7(1), 29-44.

Jaleel, S., \& Anuroofa, O. M. (2017). A Study on the Relationship between Self-directed Learning and Achievement in Information Technology of Students at Secondary Level. Universal Journal of Educational Research, 5(10), 1849-1852.

Garrison, D. R. (1997). Self-directed Learning: Toward a Comprehensive Model. Journal of Adult Education Quarterly, 48(1), 18-33.

Garrison, D. R. (2015). Thinking Collaboratively: Learning in a Community of Inquiry. Florence, KY: Taylor and Francis.

Gibbs, G. (1988). Learning by Doing: A Guide to Teaching and Learning Methods. Oxford: Oxford Further Education Unit.

Helyer, R. (2015). Learning through Reflection: The Critical Role of Reflection in Work-Based Learning (WBL). Journal of Work-Applied Management, 7(1), 15-27.

Hsu, T.-C. (2017). Learning English with Augmented Reality: Do Learning Styles Matter? Computers \& Education, 106, 137-149. https://doi.org/10.1016/j.compedu.2016.12. 007.

Hickson, H. (2011). Critical Reflection: Reflecting on learning to be Reflective. Journal of Reflective Practice, 12(6), 829-839. doi: 10.1080/14623943.2011.616687

Lee, C., Yeung, A. S., \& Ip, T. (2017). University English Language Learners' Readiness to Use Computer Technology for Self-directed learning. System, 67, 99-110. https://doi. org/10.1016/j. system.2017.05.001.

Lee, K., Tsai, P. S., Chai, C. S., \& Koh, J. H. L. (2014). Students' Perceptions of Self-directed Learning and Collaborative Learning With and Without Technology. Journal of Computer Assisted Learning, 30(5), 425-437. doi: 10.1111/jcal.12055

McLoughlin, C., \& Lee, M. J. W. (2010). Personalised and Self-regulated Learning in the Web 2.0 era: International Exemplars of Innovative Pedagogy using Social Software. Australasian Journal of Educational Technology, 26(1), 28-43.

Moodlerooms. (2012). About Moodle. Retrieved June 22, 2012 from http://www.moodlerooms.com/resources/ moodle-resources/.

Mohamed Abdullah Turky. (2016). Promoting Reflective Thinking Skills by Using Web 2.0 Application. https://doi.org/10.2139/ssrn.2758239

Moradi, H. (2015). The Role of Technology in the Development of Language Skills. International Journal of English and Education, 4(1), 112-117.

Moradi, H. (2017). The Impact of M-learning on Second Language Learning Process among University Students. Modern Journal of Language Teaching Methods, 7(8), 109-115.

Rashid, T., \& Asghar, H. M. (2016). Technology use, Self-directed Learning, Student Engagement and Academic Performance: Examining the Interrelations. Computers in Human Behavior, 63, 604-612.

Rico, R., \& Ertmer, P. A. (2015). Examining the Role of the Instructor in Problem-centered Instruction. TechTrends Tech Trends, 59(4), 96-103.

Rivenburg, C. R. (2015). Instructional Design Strategies and their Effect on Self-directed Learning in Online Learning. In Doctoral dissertation. MN: Capella University.

Song, D., Bonk, C. J., \& Whiting, J. (2012, November). Motivational and Self-regulated Learning Factors of Informal and Extreme Learning. Paper presented at the third annual virtual Global Education Conference. Retrieved from https://sas.elluminate. com/d. jnlp?sid=2008350\&password=GECPart223 
Sridharan, B., Deng, H., Kirk, J., \& Corbitt, B. (2010). Structural Equation Modeling for Evaluating the User Perceptions of E-learning Effectiveness in Higher Education. Paper presented at the 18th European conference on Information Systems, Pretoria, South Africa.

Schon, D. A. (1983). The Reflective Practitioner. New York: Basic Books.

Tanner, D. (2012). Promoting Student Metacognition. CBE Life Sci Educ, 11(2), 113-199.

Thompson, N. (2008). The Critically Reflective Practitioner. Basingstoke: Palgrave Macmillan.

Tulagan, B. (2013). Meet Generation Z: The Second Generation with the Giant "Millennial" Cohort. Rainmaker Thinking. Retrieved August 31, 2013, from http://www.rainmakerthinking.com/assets/ uploads/2013/10/Gen-Z-Whitepaper.pdf

Zepeda, C. D., Richey, J. E., Ronevich, P. \& Nokes-Malach, T. J. (2015). Direct Instruction of Metacognition Benefits Adolescent Science Learning, Transfer, and Motivation: An in vivo study. Journal of Educational Psychology, 107(4), 954-970.

Zimmerman, B. J. (2002). Becoming a Self-Regulated Learner: An overview. Theory into Practice, 41(2), $1-37$.

Zimmerman, B. J. (2008). Investigating Self-Regulation and Motivation: Historical background, Methodological Developments, and Future Prospects. AmJ Educational Research, 45(1), 166-183.

Zimmerman, B.J., \& Schunk, D.H. (2004). Self-regulating Intellectual Processes and Outcomes: Social Cognitive Perspective. In D.Y. Dai, \& R.J. Stenberg (Eds.), Motivation, Emotion, and Cognition: Integrative perspectives on intellectual functioning and development (pp. 323-350). Mahwah, NJ: Erlbaum. 